\title{
Localization Management and Practice of Transmission Line
}

\author{
Jintao $\mathrm{Yu}^{1, \mathrm{a}}$, * Yang Jia ${ }^{1, \mathrm{~b}}$, Yonggang $\mathrm{Zhou}^{1, \mathrm{c}}$ \\ ${ }^{1}$ Power Supply Branch of Xinyang, State Grid Henan Electric Power Company, Xinyang, Henan, \\ China, 464000 \\ ${ }^{*}$ Corresponding Author: Jintao Yu \\ ${ }^{a}$ email, ${ }^{b}$ email, ${ }^{c}$ email
}

Keywords: localization, Region, Implementation, Measures

\begin{abstract}
The localization management of transmission lines can not only take the advantages of geography, information advantage, location and traffic of each territorial power company, but can also improves the efficiency of fault inspection and fault recovery to the reliability of power supply substantially.
\end{abstract}

\section{Introduction}

With the rapid development of urban and rural construction, the channel environment of transmission line becomes more and more complex. Due to the short circuit of the foreign body, crane the touch line, illegal construction, theft and other causes of line tripping up for the first of all kinds of transmission line trip, resulting in power grid enterprises huge economic losses, has a great effect on the safe operation of the electric network.

Xinyang region is long and narrow, with $230 \mathrm{~km}$ distance from the east to the west. The management and the greater the radius, the higher voltage rating of power transmission lines, inspection management more easy oversight, off-site to solve the processing problem appears to be more and more convenient and timely. The national network of Xinyang power supply company transmission operation examination room is mainly responsible for Xinyang 220 kilovolt line 38, 39 110 kilovolt line and $35 \mathrm{kV} 312020 \mathrm{~km}$ line of operation and maintenance, maintenance, and testing work and every year and put into operation a new line nearly 100 kilometers. With the rapid growth of the line mileage, and the total amount of transmission and maintenance personnel remain unchanged, and the aging of the year, and the fault of the missing member and other issues. Traditional line operation and maintenance mechanism in line to guarantee efficiency, quality, prevent external damage, clear channel obstacle, due to lack of operation and maintenance of the power grid has become a professional development constraints, it is difficult to adapt to the new situation of the lean management of the transmission line. Through the development of territorial management of the transmission, which can give full play to the various territorial power companies' geographical advantage, information advantage, location advantage and traffic advantage, and in fault inspection and fault recovery to improve work efficiency, greatly enhance the reliability of power supply.

\section{Work Ideas}

In order to improve the transmission line operation and maintenance support capability and improve the line to run external environment as the main target, give full play to the counties and 
the outskirts of the division of the territorial resources advantage, the city, the voltage level of transmission lines in accordance with the administrative region are divided into counties, and the suburban segment, the county and suburban division is responsible for channel within the territorial line inspection, clear channel barrier and protection of power facilities, etc., to carry out transmission line channel of territorial management, so as to effectively solve the problem of fault tree, the line "three violations", theft and destruction of substandard breaking prevention and control of the risks is difficult, difficult and. At the same time, innovative management, combined with the channel localization to carry out the line ontology localization inspection work, ease the contradiction between the rapid increase in the size of the line and the relative shortage of personnel. Preliminary formed combining the protection of power facilities, professional management and localization of door, professional inspection and territorial of inspections combination, power shipment inspection room and territorial patrol team combination of "three in one" line operation and maintenance of security system, out of the new road of a management reform and innovation.

In recent years, due to the construction operations in the channel of overhead transmission line protection zone, construction plastic greenhouse, planting trees, illegal buildings housing reasons, outside force in the transmission line failure events have occurred from time to time and with large number of industrial, industrial park construction, channel transmission lines protection zone of concrete pump truck, cranes and other large special vehicle touch line. Illegal tree houses phenomenon more and more, with the development of economy and society, line protection zone high pole trees and illegal construction has become the great hidden danger to the safe operation of the line, channel cleaning has become the one of the difficulties in operation and maintenance. At present, some provinces and cities power grid transmission line of territorial management present situation of implementation of line of territorial management advantages and disadvantages are analyzed, put forward line of territorial management ideas from the basic circuit operation of cross line operation divided the dividing point, line fault trip management, comprehensive power management, channel wrecker and inspection management. Grid line of territorial management characteristics is proposed to give full play to the advantages of territorial management, strengthen cross line fault processing and coordination, the strengthening of the comprehensive power plan formulation, execution and assessment, the implementation of classification support line and the mass line protection system, emphasis on the management of the whole process of the transmission and from the source to the concept, achieve zero defect line project handed over to run.

\section{Performance of Organization and Implementation}

Compile Implementation Program of Project. According to province, city company management innovation project work requirements, combined with the Xinyang transmission line of territorial management present situation, clear the work of innovative ideas, preparation of the implementation plan determined tasks in each stage, to guarantee the steady and orderly progress of the work.

Clarify Responsibility Zone of Line. According to the territorial management needs, to determine the city company as the lead, 8 County companies and 3 suburban customer service centers as the main body, the implementation of the specific implementation of the township power supply system.

Currently plans to implement the territorial management of transmission lines a total of 104, of which 35 total $1138.127 \mathrm{~km} 220 \mathrm{kV}$ line, $110 \mathrm{kV}$ lines totaling $399.522 \mathrm{~km}, 35 \mathrm{kV}$ lines 30 total of $353.474 \mathrm{~km}$. Lines covering eight county companies and 3 suburban customer service centers under the jurisdiction of the region. According to the requirements of the project implementation, the 
transmission line localization management responsibility should be implemented to the localization of the village level. To this end the company's transmission inspection room through the GPS inspection machine combined with electronic map, clearly divided city, county, township, Village Inspection responsibility area. According to the path diameter to establish "Xinyang power supply company transmission facilities apanage management ledger", clear voltage grade, name of the line, territorial units, transit towers, crossing length, territorial power, territorial village, transit length, responsible for telephone and other information, the input system. At the same time arrange the relevant personnel in the field with the localization of management personnel to confirm one by one, to ensure that the regional division is correct, the responsibility to put in place.

Develop Training Work of Management. According to the localization of management work in progress arrangement, this month plans to organize relevant personnel of the territorial of units to the management of the specific implementation of the territorial management knowledge training, clear territorial management implementation the responsibility of units and responsible persons, impart localization management process in various measures of emergency handling, as a territorial management work steadily lay the foundation of knowledge.

Since April 7, city transmission company transport inspection room personnel for the scene teaching way of 8 counties Bureau and three suburban division territorial management and implementation of personnel training, organized training seminars for 9 times and the total number of participating in the training of more than 400 persons. The main content of the training of power facilities protection and safe operation, transmission line localization operation and maintenance and management, transmission line fault, such as the rapid approach.

\section{Perfect Relevant Work Management Methods and Indicator System}

Establish and improve management system. According to the demands for promoting the transmission line of territorial management work, formulated the the national network of Xinyang power supply company transmission facilities localization work management stipulates that "and the area of Xinyang power supply of $35 \mathrm{kV}$ and above transmission lines of territorial management implementation details", has been clear about the organization, responsibilities, work requirements and incentive measures.

Perfect relevant work requirement to ensure management system work properly. Electrician of territorial units according to apanage of transmission line daily maintenance work required to work: rural electrician every 15 days under the jurisdiction of the line for a patrol, patrol line protection zones within the risk source of threat to the safety of the line and a line device has no obvious abnormality, and the channel line maintenance, cleaning, including content. At the same time, to carry out the work of line inspection, the masses of the line along the transmission facilities to protect the publicity and education. Territorial units after the inspection to fill in the transmission facilities territorial management of the work of the monthly report, 28 days before the monthly report by the OA transmission inspection room.

When the territorial units of electrician in the inspection process found serious and above defects, fill out the "channel hidden statistical table", and report immediately, by the transmission operation examination room to classify defects, and reported to the operation and maintenance department formulate defect elimination plan, implementation of defect elimination. After the completion of the defect elimination to inform the local power supply. Transmission inspection room will be a monthly report of the missing records issued a territorial supply, the two sides confirmed and retained.

When the line fault trip, the local electrical after receiving the notice of the accident, should be fast and timely on the territorial transmission line inspection, when the failure point found, 
immediately reported. Power shipment inspection room of the fault for site analysis, and arrange equipment failure repair work, by the territorial units with facilities management unit to carry out accident repair, to assist in the surrounding masses visits, maintain an accident processing peripheral environment order, the line outage time is reduced to the minimum, to improve the reliability of power supply, reduce line outage losses.

For channel endanger the safe operation of the transmission line illegal construction, housing and other behavior and transported by the transmission testing laboratory evidence and to harm people issued a "hazard informed book, to fill in the" hazard emergency power facilities outage notice ", after approval by the operation Department examined and signed by the leaders of the company, is performed by the power supply. Territorial management unit received a notice of a blackout, to take effective measures to ensure the implementation of the power outage notification.

Improve management objective system and indicator values. For protecting the transmission line of territorial management work was carried out smoothly, combined with Xinyang company's reality, by the municipal company formulated the localization work target management system, including transmission of lean management, benchmarking and enterprises responsible for the people of the three performance index system. The "transmission of lean management indicators and benchmarking indexes, including operation, daily work and annual inspection and evaluation of three kinds of indicators, the responsible person of the enterprise performance indicators include the" 110 (66) $\mathrm{kV}$ and above overhead transmission line fault outage rate. $35 \mathrm{kV}$ and above the cable line fault outage rate 2. And set the following management objectives: 110 (66) $\mathrm{kV}$ and above overhead transmission line fault outage rate less than or equal to $1 \%, 35 \mathrm{kV}$ and above cable line fault outage rate is less than or equal to $1 \%, 110 \mathrm{kV}$ and above transmission lines fault outage time is reduced by $50 \%$, inspection report timely reporting rate of $100 \%$.

Carry Out Line Defect Handover Work. According to the localization of management work in progress arrangement, in order to clear territorial management effect and urge localization electrician to carry out regular inspections, management innovation team will present transmission line of defects according to the localization of the implementation of the unit's area of responsibility division, the localization of the implementation of the defects in the unit's area of responsibility to clear out, to facilitate subsequent to the territory electrician patrol work effect was evaluated.

\section{Focus of Future Work}

We should promote the steady implementation of territorial management. The territorial management implementation unit to carry out transmission line of territorial management work in accordance with the area of responsibility, regularly carry out line inspection work and the result of the inspection report, transmission operation inspection chambers, to monitor the serious defects and critical flaws, and according to the city power shipment inspection room notice good accident line patrol and Paul electric wire guard work. Through irregular spot checks of transmission inspection room by the city company, the GPS patrol aircraft and other means can check and supervise the work to ensure that the localization of management work.

\section{References}

[1] Dong Zong, Wu Fengliang, Tao Qian, Enterprise Reform and Management, Vol. 24 (2016) No 8, p.18-19

[2] Peng Xiangyang, Zhou Huamin, Wei Yuanhang, Guangdong Electric Power, Vol. 22 (2009) No 12, p.72-77 
[3] Zeng Quanfu, Rural Electician, Vol. 24(2016) No 5, p.12

[4] Guan Liping, Guan Huaping, Shanxi Electric Power, Vol. 25(2015) No 3, p.49-52 